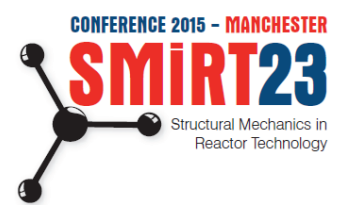

Abstract Transactions, SMiRT-23

Manchester, United Kingdom - August 10-14, 2015

Paper ID 542

\title{
OVERVIEW OF FRENCH PROPOSAL OF UPDATED AUSTENITIC SS FATIGUE CURVES AND OF A METHODOLOGY TO ACCOUNT FOR EAF
}

\author{
Thomas Métais ${ }^{1}$, Stéphan Courtin ${ }^{2}$, Pierre Genette ${ }^{1}$, Laurent de Baglion ${ }^{2}$, Cédic Gourdin ${ }^{3}$, Jean- \\ Christophe Le Roux ${ }^{4}$, Stéphane Marie ${ }^{2}$
}

${ }^{1}$ EDF SEPTEN, Avenue Antoine Dutriévoz, 69100 Villeurbanne, FR

${ }^{2}$ AREVA NP, 1 Place Jean Millier, 92400 Courbevoie, FR

${ }^{3}$ CEA, DEN, DM2S, SEMT, LISN, 91191 Gif-sur-Yvette, FR

${ }^{4}$ EDF Les Renardières, 77818 Moret-sur-Loing Cedex, FR

\begin{abstract}
Environmentally Assisted Fatigue is receiving nowadays an increased level of attention not only for new builds but also for the installed bases which are currently having their lives extended to 60 years in various countries. To formally integrate these effects, some international codes have already proposed code cases. More specifically, the ASME code has used the NUREG/CR-6909 [1] as the basis for Code Case N-792 [2] and suggests a modification of the austenitic stainless steels fatigue curve combined with a calculation of an environmental penalty factor, namely $\mathrm{F}_{\mathrm{en}}$, which is to be multiplied by the usual fatigue usage factor.

The various methodologies proposed are not finalized and there is still a significant level of discussion as can be illustrated by the recent update of NUREG/CR-6909 [3]. In this context, EDF, AREVA and the CEA have also submitted two RCC-M Rules in Probatory Phase (RPP) (equivalent to ASME code-cases) to AFCEN to propose respectively an update of the fatigue curve for austenitic stainless steels and a methodology to incorporate EAF in fatigue evaluations.

The approach is globally similar to the one in the ASME code: it consists in an update of the mean air and design fatigue curves as well as the calculation of an environmental penalty factor. Nevertheless, the methodologies differ in their detailed implementation by especially introducing the $\mathrm{F}_{\text {en-integrated }}$ which accounts for the environmental effects already covered by the fatigue curves. This paper is the sequel to the proposal already described in [4] [6].
\end{abstract}

\section{Introduction}

As many countries are now working to extend the life of their existing power plants, a thorough inventory of the various effects that could potentially represent a hazard to a safe long term operation is necessary: the effects of the PWR environment on the primary system components are one of them. Since 2007, the USA with the NUREG/CR-6909 [1], have now included the evaluation of environmental effects in their official regulation, based on the Environmental correction factor $\mathrm{F}_{\mathrm{en}}$.

Two RCC-M Rules in Probatory Phase (RPP) have been officially submitted at the end of 2014 to ASN/IRSN and to AFCEN. These were developed as part of a joint three-party effort involving EDF, AREVA and CEA. The first RPP pertains to the austenitic stainless steel fatigue curve while the second RPP introduces a method to incorporate environmental effects in the calculations and presents $\mathrm{F}_{\text {en-integrated which accounts for the environmental effects already covered }}$ by the fatigue curves. 
There were essentially two main drivers that motivated EDF/AREVA/CEA to write two RPP which included some divergence with the American NUREG/CR-6909 [1] and Japanese JSME [7] methods:

- To have rules that are applicable to representative steels procured according to the RCC-M code and hence representative of the steels on the fleet of reactors designed using the RCC$M$ code (EDF fleet, $\mathrm{EPR}^{\mathrm{TM}}$, etc...), which are less numerous than in ASME and often have more stringent requirements on their composition than their international counterparts;

- To establish a reasonably conservative methodology to incorporate environmental fatigue effects, representative of the international experience feedback and of the test campaigns that have been led around the world. The objective of adjusting the conservatism of the methodology is to ensure that conventional fatigue methods can still be used in Stress Report analyses, without having to systematically depend on non-codified and often more complex methods (elasto-plastic analysis, etc...) with limited experience feedback.

Previous publications [4] [6] have described the work that was led within the EDF/AREVA/CEA working group over the past 3 years. This current paper aims at presenting the more recent results obtained as well as summarizing the contents of the two RPP.

The first part of this paper will recall the scope of applicability of the methodology proposed. The second part presents the contents and summarizes the technical justification of the first RCC$\mathrm{M}$ rule on the austenitic stainless steel fatigue curve. The third part presents the contents of the second RCC-M RPP on the incorporation of environmental effects into Stress Report calculations.

\section{Scope of applicability of the rules}

The rules that have been submitted to ASN/IRSN and AFCEN cover austenitic stainless steels. More specifically, the focus in France is essentially given to 304L/316L austenitic stainless steels for three reasons:

- On the primary side, low-alloy steels are covered by the cladding so they are not exposed to the primary environment while on the secondary side, the oxygen content is not sufficient to justify taking into account environmental effects for carbon steels;

- Cast duplex stainless steels and Ni-Cr-Fe Alloys are considered to be covered by the same fatigue curve as austenitic steels, as is also concluded in NUREG/CR-6909, in ASME BPV and RCC-M codes. This will be verified later only by a few additional tests on these heats;

- Almost all the primary loop wetted surfaces of the 58 nuclear reactors in France are 304L or $316 \mathrm{~L}$ austenitic stainless steels, which is why the experimental testing campaigns in France have focused on these grades. In addition, the material specification of the few areas in 304 and 316 austenitic stainless steels exhibit very stringent requirements in carbon composition which makes these grades, in a first approach, close to the $304 \mathrm{~L}$ and $316 \mathrm{~L}$.

The situation concerning the cast stainless steels and Ni-Cr-Fe Alloys may evolve in the long run as some possible testing has been recently discussed for these types of steels.

Nevertheless, as this point in time, the French experimental efforts have been focusing, and will continue to focus in the near future, on $304 \mathrm{~L} / 316 \mathrm{~L}$ austenitic stainless steels nuclear grades. 
To summarize, the fatigue curve RPP covers the austenitic stainless steels as well as the NiCr-Fe alloys. The second RPP provides rules only for the austenitic stainless steels.

\section{RPP for an austenitic SS Fatigue Curve}

This first rule only presents the new fatigue curve so the RPP document in itself is rather short. As a reminder, the data used for the analyses is presented in Table 4.

The next sections will summarize the choices made for the mean air curve, the coefficients to transition from the mean air curve to the design curve and finally a word on the mean stress.

\subsection{Mean air curve}

NUREG/CR-6909 [1] proposes the following equation for the mean air curve:

$$
\ln \left(\mathrm{N}_{25}\right)=6.891-1.92 \ln \left[\frac{\Delta \varepsilon}{2}-0.112\right]
$$

Figure 1 shows the plot of the estimated number of cycles using this equation versus the number of cycles measured experimentally for all the data obtained in France.

Defining the ratio of the estimated number of cycles to the measured one as $\gamma_{\mathrm{N}}$, it is possible to calculate the mean " $\mathrm{m}$ " of the logarithm of this parameter for the entire set of $\mathrm{n}$ data points collected, as well as its standard deviation, $\sigma$. The two are calculated as follows:

$$
\begin{gathered}
\mathrm{m}=\frac{1}{\mathrm{n}} \sum \log \left(\gamma_{\mathrm{N}}\right) \\
\sigma=\sqrt{\frac{1}{\mathrm{n}} \sum \log \left(\gamma_{\mathrm{N}}\right)^{z}}
\end{gathered}
$$

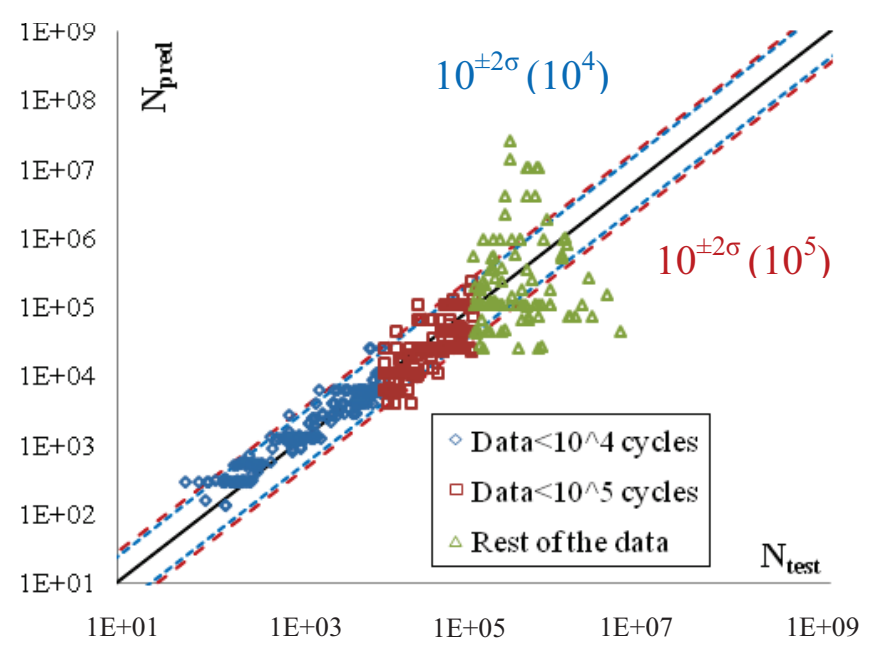

Figure 1 - Plot of the predicted number of cycles vs. the measured number of cycles for French air data

As can be seen in Table 1, the mean and the standard deviation were calculated for the French data up to $10^{4}$ and $10^{5}$ cycles in order to carry out comparisons with Reference [16]. The same calculation was performed for the data from NUREG/CR-6909 Rev. 0 [1].

Table 1 - Statistical information for the various international data

\begin{tabular}{|l|c|c|c|c|}
\cline { 2 - 5 } \multicolumn{1}{c|}{} & Mean air curve equation used & Average & Standard deviation & $\mathbf{R}^{2}$ \\
\hline French data & NUREG/CR-6909 & -0.01 & 0.23 & 0.78 \\
\hline Japanese 304 SS data & Reference [16] & -0.03 & 0.20 & - \\
\hline Japanese 316 SS data & Reference [16] & 0.08 & 0.31 & - \\
\hline $\begin{array}{l}\text { NUREG/CR-6909 [1]and Reference } \\
\text { [16] data }\end{array}$ & NUREG/CR-6909 & 0.09 & 0.32 & 0.80 \\
\hline $\begin{array}{l}\text { Information given in NUREG/CR- } \\
\mathbf{6 9 0 9}[1]\end{array}$ & NUREG/CR-6909 & - & - & 0.85 \\
\hline
\end{tabular}


In addition, the coefficient of determination $\mathrm{R}^{2}$ was also calculated for all the experimental data from France in order to compare it with the values calculated with the data from NUREG/CR-6909 and Reference [16]. Reference [1] also indicates values of $\mathrm{R}^{2}$ of 0.85 for the data up to $10^{5}$ cycles used within this reference, of 0.83 for the data contained in Reference [16] only and of 0.57 for ASME code.

The $95 \%$ confidence limit $\left(10^{ \pm 2 \sigma}\right)$ based on the value calculated for the French data up to $10^{4}$ and $10^{5}$ cycles were added to figure 1 . As can be seen, most of the experimental data is gathered around the $\mathrm{y}=\mathrm{x}$ curve with a low standard deviation, equal or lower than the number obtained with the NUREG/CR-6909 data and comparable to the values given in the Reference [16].

The values of $\mathrm{R}^{2}$ are of the same order of magnitude as the ones given in NUREG/CR-6909 and indicate that the curve given in the latter corresponds well to the French data.

In conclusion, the French position is to select the NUREG/CR-6909 mean air curve in [3] as it represents adequately the French experimental data.

\subsection{Construction of the fatigue curve}

In order to take into account the parameters that are unaccounted for in air tests, two coefficients are then applied to the mean air curve. The first coefficient is on the number of cycles and the current proposal that can be found in NUREG/CR-6909 Rev. 1 [3] states that a coefficient of $10-12$ can be selected. The second coefficient in [3] is applied on the strain amplitude and is equal to 2 . The design curve is built by correcting for mean stress, then taking the curve that is the minimum between the corrected air curve, further corrected by one coefficient or the other.

\section{1) Coefficient on the number of cycles}

The French proposal breaks down the coefficient on the number of cycles into three contributions. In order to account for the links between the various effects as well as various other effects unaccounted for, the following set of coefficients is proposed:

- Coefficient on material variability and data scatter: this coefficient is the exact same as the one in NUREG/CR-6909 and accounts for the scatter inherent to fatigue testing and the variability among materials and different grades;

- Coefficient for component effects: this coefficient covers in particular the effect of surface roughness, size and also the structural effect, especially in the case of thermal loadings;

- Coefficient for loadings: this coefficient covers among others the effect of a multi-axial loading as well as variable amplitude loading [17].

Schematically, these three coefficients address respectively the experimental uncertainties in the laboratories, the structural uncertainties when switching from a specimen to a full size component and finally the uncertainties on loadings. The values for these three coefficients were determined using the experimental data available.

For the coefficient on material variability and data scatter, a method similar to NUREG/CR6909 [1][3] was used. Given N the number of cycles, $\varepsilon$ the strain amplitude and B and $\mathrm{C}$ two constants (for austenitic steels, $\mathrm{B}=1.92$ and $\mathrm{C}=0.112$ ), the aim is to determine the impact of material variability on the coefficient $\mathrm{A}$ defined as follows:

$$
\ln (\mathrm{N})=\mathrm{A}-\mathrm{B} \ln (\varepsilon-\mathrm{C})(4)
$$

In the $(\mathrm{N}, \varepsilon)$ domain, this will indeed correspond to a shift of the fatigue curve along the number of cycles. The following general steps are followed: 
1- The whole data set is split into sub-groups of data points according to the laboratory, the loading type (temperature levels, loading signal applied (i.e. saw-tooth or other)) and the material grade. For each sub-group, the mean $\mathrm{A}_{\mathrm{i}, \mathrm{m}}$ and the $5^{\text {th }}$ and $95^{\text {th }}$, respectively $\mathrm{A}_{\mathrm{i}, 5}$ and $\mathrm{A}_{\mathrm{i}, 95}$, prediction intervals using the t-distributions are then determined;

2- A normal statistical description is then fitted to all the values of $A_{i, m}$, enabling the calculation of the median value $\mathrm{A}_{\mathrm{m}}$ as well as the standard deviation of the data set $\mathrm{sd}$ values and the $\alpha$ th percentiles $\mathrm{A}_{\alpha}$;

3- As per Reference [16], the overall coefficients are then calculated by determining the $10^{ \pm 2 \mathrm{sd}}$ boundaries.

This enables to obtain a coefficient of $2.1-2.8$ on data scatter: more details on the overall method can be found in Reference [6]. It should be noted though that the values of $A_{m}$ and sd are the ones used for the calculation of the overall coefficient, as will be seen later.

Concerning the coefficient on component uncertainties, one effect covered is surface roughness. Work carried out by AREVA [13][14][15] analyses the effect of surface roughness in PWR environment as well as in air environment: this brought some valuable information regarding the comparative effect of surface roughness in both those environments (see Figure 2).

Keeping all other quantities equal, when comparing a data point obtained in air environment with and without a rough surface, the coefficient on the life ranges between $\sim 1.5$ to 2.5 . In PWR environment, this exact same coefficient ranges from $\sim 1.0$ to 2.0. Adding an extra conservatism to cover other uncertainties, the RPP finally takes a coefficient ranging from 2.0 to 3.0 in air and 1.5 to 2.5 in PWR. It should be emphasized here that this proposal is very conservative:

- For rough surface finishes, experimental data [13][14][15] shows that smaller coefficients than the ones proposed above are applicable due to surface roughness. Moreover, there is no size effect with this surface finish,

- For a polished specimen, a factor on size only should apply and NUREG/CR-6909 Rev. 0 [1] only recommends a factor ranging from 1.2 to 1.4 ,

- Thermal loadings or areas of stress concentration generating gradients through the surface wall have a beneficial effect on the life of a structure and are not accounted for in the RPP.

Finally, concerning the coefficient on loadings, and more particularly the coefficient on multi-axiality, the difficulty lies in the interpretation of these tests. The first problem arises when having to choose an equivalent strain, which is necessary to compare the strain from a multi-axial test to a curve obtained with uni-axial testing. Second, the definition of crack initiation is also problematic: for some tests such as Fat3D [19], the experiment had to be stopped in order to visually inspect the surface of the specimen, so there was no possible way to have an accurate estimation of when initiation occurred.

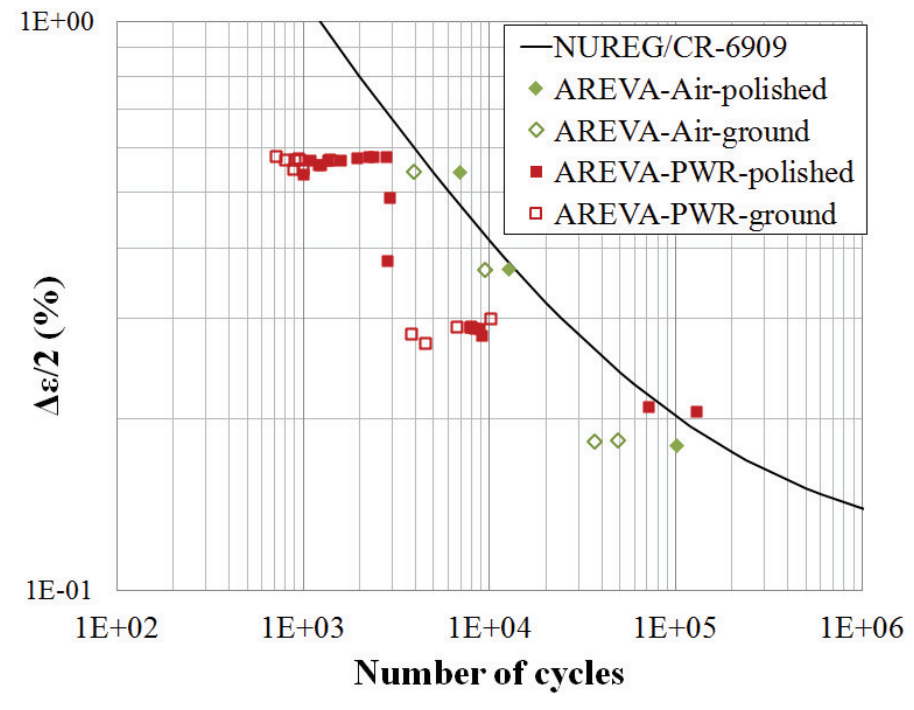

Figure 2 - Data points obtained through the AREVA test campaign [13][14][15] 
The following proposal is made for the definition of the equivalent strain to carry out the interpretation of multi-axial tests:

$$
\begin{array}{|c|}
\hline \Delta \varepsilon_{\text {eq }}=\frac{1}{1+v} \max \left(\left|\Delta \varepsilon_{I}-\Delta \varepsilon_{\mathrm{II}}\right|,\left|\Delta \varepsilon_{\mathrm{I}}-\Delta \varepsilon_{\mathrm{III}}\right|,\left|\Delta \varepsilon_{\mathrm{II}}-\Delta \varepsilon_{\mathrm{III}}\right|\right)_{\text {elas }} \\
\hline+\frac{1}{1+0.5} \max \left(\left|\Delta \varepsilon_{\mathrm{I}}-\Delta \varepsilon_{\mathrm{II}}\right|,\left|\Delta \varepsilon_{\mathrm{I}}-\Delta \varepsilon_{\mathrm{III}}\right|,\left|\Delta \varepsilon_{\mathrm{II}}-\Delta \varepsilon_{\mathrm{III}}\right|\right)_{\text {plas }} \\
\text { Plastic contribution }
\end{array}
$$

Where $\varepsilon_{\mathrm{I}}, \varepsilon_{\mathrm{II}}$ and $\varepsilon_{\mathrm{III}}$ are the three principal strains, $\varepsilon_{\mathrm{eq}}$ is the proposed equivalent strain "elas" is the elastic contribution and "plas" is the plastic contribution and $v$ is Poisson's ratio.

It can be seen that in the case of a purely elastic strain, the equivalent strain is equal to a Tresca strain, which is consistent with the quantities used in fatigue analyses in the RCC-M code.

Given the equation (5) above, it is possible to plot the multi-axial data points obtained for the tests INTHERPOL [18], FAT3D [19], FABIME2 [20][21] and also work led by LMT Cachan [22][23] and in the PhD by Haddar [24]. The plot can be seen on Figure 3. For the Fat3D and LMT Cachan data points, the crack initiation could not be easily determined so a horizontal bar was plotted: the crack was initiated somewhere between the two ends of the bar. Concerning the FABIME2 points, there was no access to an elastic and plastic strain contribution so a vertical bar was plotted: the top end of the bar indicates that the strain is all elastic while the bottom end of the bar indicates the strain measured during the test. The reality is somewhere in between: for the data points in the high-cycle domain, the strain level is almost all elastic so the "real" data point will be closer to the top end of the bar.

Finally, a coefficient ranging from 1.0 to 2.0 was selected for the coefficient on loadings, as a shift of 2 on the number of cycles covers most of the data points obtained.

The global coefficient is then calculated along the same method as the NUREG/CR-6909 [1][3]: $\mathrm{A}_{\mathrm{m}}$ and $\mathrm{sd}$ obtained through the statistical analysis for material variability and data scatter are used and the shift induced by adding in the effects of the two other aggravating parameters is calculated by obtaining a value of the coefficient A incorporating all effects. The coefficient can then be calculated as the exponential of the difference between the A from the mean air curve (6.891) and the A obtained. The coefficient obtained in air is of 7.0 and the coefficient obtained in PWR is 6.0. Figure 7 shows the overall

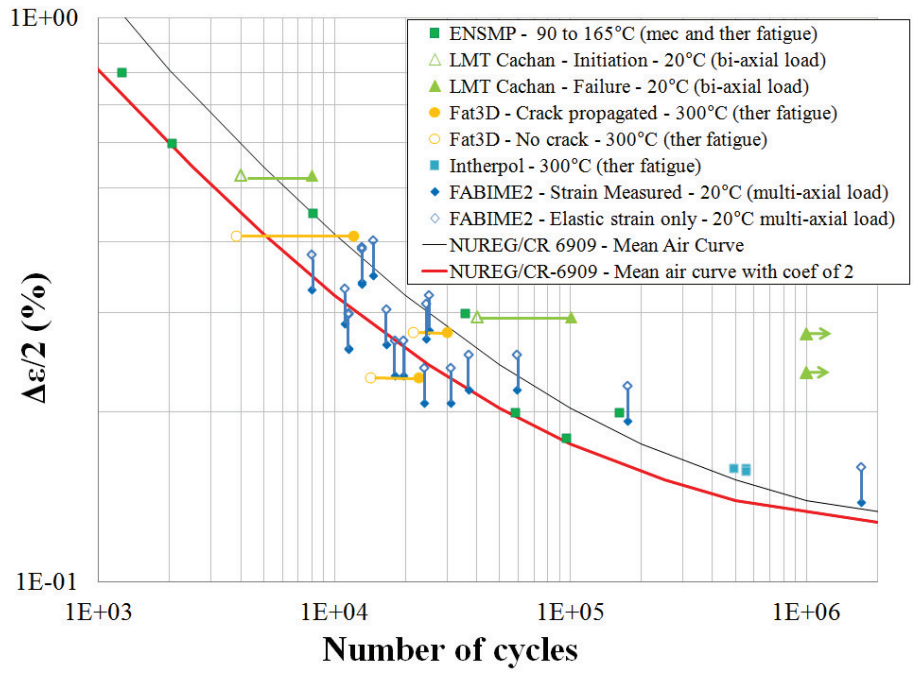

Figure 3 - Data points obtained through various test campaigns [17] - [24] methodology for obtaining these coefficients.

\section{2) Coefficient on the strain amplitude}

The coefficient on strain amplitude is evaluated by using four different statistical methods applied to the high-cycle fatigue data in air. These four methods are: the prediction intervals [26], 
the Wilks percentiles or order statistics, the maximum likelihood [27] and the quantile regression [28]. This work is summarized in the Reference [25] and will not be detailed here.

Table 2 - Summary of coefficients on strain amplitude obtained

\begin{tabular}{|c|c|}
\hline Method used & $\begin{array}{c}\text { Range of coefficients on the strain amplitude } \\
\text { obtained }\end{array}$ \\
\hline Prediction intervals & $1.2-1.4$ \\
\hline Wilks percentiles (order statistics) & $1.1-1.4$ \\
\hline Maximum likelihood & $1.1-1.3$ \\
\hline Quantile regression & $1.1-1.4$ \\
\hline
\end{tabular}

The Table 2 summarizes the coefficients obtained through the application of these four methods. It can be seen that all the coefficients obtained are less than 1.4. The overall coefficient on the strain amplitude that was selected was therefore equal to 1.4.

Table 3 - Numerical values for the new RCC-M curve

Note: $E_{c}=179 \mathrm{GPa}$

\begin{tabular}{|c|c|}
\hline Number of cycles & Stress Amplitude (MPa) \\
\hline 10 & 6088 \\
\hline 20 & 4304 \\
\hline 50 & 2746 \\
\hline 100 & 1975 \\
\hline 200 & 1437 \\
\hline 500 & 968 \\
\hline 1000 & 735 \\
\hline 2000 & 573 \\
\hline 5000 & 432 \\
\hline 10000 & 362 \\
\hline 20000 & 313 \\
\hline 50000 & 270 \\
\hline 100000 & 248 \\
\hline 200000 & 223 \\
\hline 500000 & 193 \\
\hline 1000000 & 177 \\
\hline
\end{tabular}

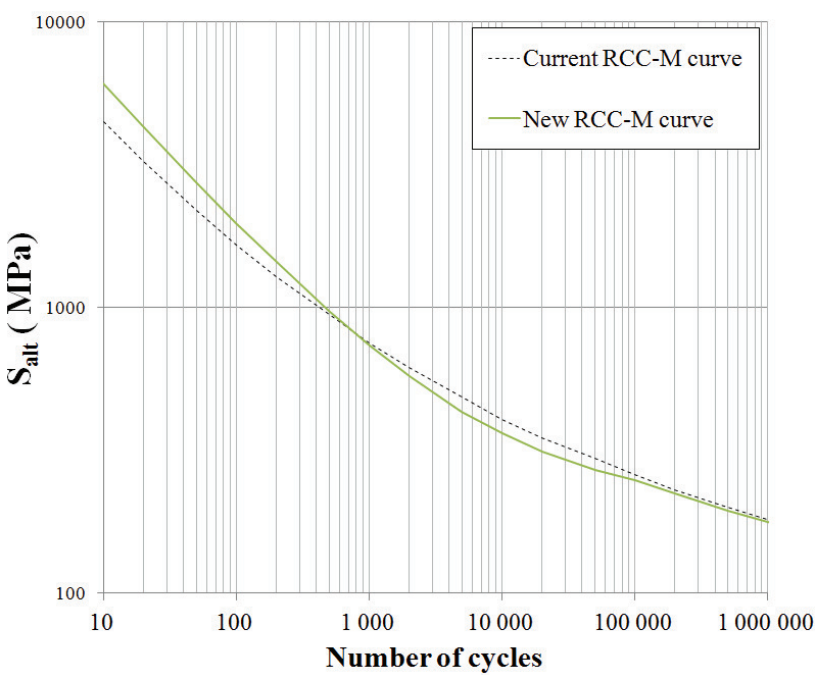

Figure 4 - New and former RCC-M fatigue curve for austenitic stainless steels

\subsection{Mean stress}

In the NUREG/CR-6909, the mean stress is incorporated in the calculations by using the modified Goodman correction. As a reminder, the modified Goodman correction can be applied as follows:

$$
S_{a l t}{ }^{\prime}=S_{a l t}\left(\frac{\sigma_{u}-\sigma_{y}}{\sigma_{u}-S_{a l t}}\right) \text { for } \mathrm{S}_{\mathrm{alt}}<\sigma_{\mathrm{y}}(6) \quad S_{\text {alt }}{ }^{\prime}=S_{\text {alt }} \quad \text { for } \mathrm{S}_{\mathrm{alt}}>\sigma_{\mathrm{y}}(7)
$$

where $\mathrm{S}_{\mathrm{alt}}$ is the alternating stress, $\mathrm{S}_{\mathrm{alt}}$ ' is the alternating stress corrected by the mean stress, $\sigma_{\mathrm{u}}$ is the ultimate tensile stress and $\sigma_{\mathrm{y}}$ is the material cyclic yield strength.

As can be deduced from the expression above, the mean stress will have no effect if the alternating stress is greater than the cyclic yield strength of the material. In the NUREG/CR6909, the values chosen for the cyclic yield strength and the ultimate tensile strength are respectively of 303.4 $\mathrm{MPa}$ and $648.1 \mathrm{MPa}$. These values are very high compared to the same 
material properties of RCC-M austenitic stainless steels: the maximum cyclic yield strength was found to be of $250 \mathrm{MPa}$ whereas the maximum ultimate tensile strength around $600 \mathrm{MPa}$. When applying the modified Goodman correction with these values, it appears that the modified Goodman correction has no effect for alternating stresses higher than the $S_{\text {alt }}$ at $10^{6}$ cycles (177 $\mathrm{MPa})$.

In the RPP, a modified Goodman correction is taken into account but has no effect in the domain less than $10^{6}$ cycles.

\subsection{Summary}

As a conclusion, the new austenitic stainless steel fatigue curve is built as follows:

- Choice of the NUREG/CR-6909 mean air curve;

- Apply factors of 10 and 1.4 on life and strain amplitude respectively;

- Take the most conservative between the two curves.

The final curve and the accompanying numerical values can be seen respectively on figure 4 and

Table 3. The value of 10 on the number of cycles was selected as it is considered that this additional margin covers part of the environmental effects (see below). It is assumed that for $\mathrm{S}_{\mathrm{alt}}<177 \mathrm{MPa}$, there is no usage factor induced.

\section{RPP for Environmental effects}

The second rule document gives instructions on how to include environmental effects in Stress Report calculations for austenitic stainless steels only. It notably introduces to a new

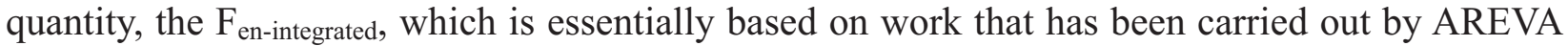
since 2005 [12][13][14][15] and on the related methodology [30].

The next sections will detail the contents of this RPP: the first section exposes the general methodology while the second section presents the exemption rules. The third and fourth sections finally present respectively how to evaluate an environmental factor and what to do after comparing it to the $\mathrm{F}_{\text {en-integrated. }}$

\subsection{General methodology}

The general methodology is best explained on the figure 5. It aims at assessing whether the former usage factor (i.e. calculated using conventional methods) is valid or if an environmental correction needs to be taken into account.

As can be seen, the detailed $\mathrm{F}_{\text {en }}$ analysis is performed if the environmental fatigue exemption rules are not met. In this case, the former CUF is not valid and must be updated by taking into account environmental effects. These specificities of the French rule will be detailed in the next sections.

Concerning the components and the zones to analyze, it is the responsibility of the analyst to make a selection. As an example, a few indications are given here:

- Any location in contact with the primary water environment;

- High CUF ;

- «Sentinel location» [29], i.e. a location that shares similar thermal transient loadings and geometrical features but which bounds other locations of the component in terms of usage factors.

The next sections give additional details on the various steps to follow. 


\subsection{Exemption rule}

Before any detailed analysis is started, the analyst can check whether a $F_{\text {en }}$ calculation is needed or not. The RPP specifies a situation where the detailed calculation is not needed: if the maximum temperature for the whole set of thermal transients contributing to the CUF exhibit a temperature that is below $200^{\circ} \mathrm{C}$, then no $\mathrm{F}_{\text {en }}$ evaluation is needed.

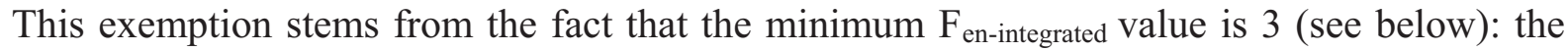
temperature associated to a $\mathrm{F}_{\text {en }}$ of 3 and assuming a maximum strain rate is $200^{\circ} \mathrm{C}$, using Annex A formula. If this exemption rule is not met, the analyst will have to perform an environmental calculation.

\section{Evaluation of the Environmental factor for a transient pair}

The environmental factor formulas that are used are identical to the latest revision of NUREG/CR-6909 [3]. This expression is given in Annex A as a reminder.

It is considered that environmental effects have a detrimental effect only on transient portions where the strain rate is positive, as can be found in NUREG/CR-6909 [1][3].

The RPP offers two ways of evaluating the $\mathrm{F}_{\text {en }}$ : the first way is a simplistic approach by simply using the formula given in Annex A whereas the second method is a detailed calculation that can be applied only to RCC-M type B-3200 and ZE-200 fatigue analyses (similar to ASME NB-3200 with full transient description and combination). In most cases, given the complexity of the transient combinations in Stress Reports, the second methodology will be used.

To carry out a detailed evaluation, these four steps are followed:

1) Re-arrange the transients so that the $F_{\text {en }}$ is calculated on the portions where the strain rate is positive and calculate the total strain amplitude reached;

2) If necessary, modify the total strain amplitude to account for any local plastic strain ;

3) Divide the positive strain rate portions into increments and calculate the $F_{\text {en }}$ for each small increment using the formula given in

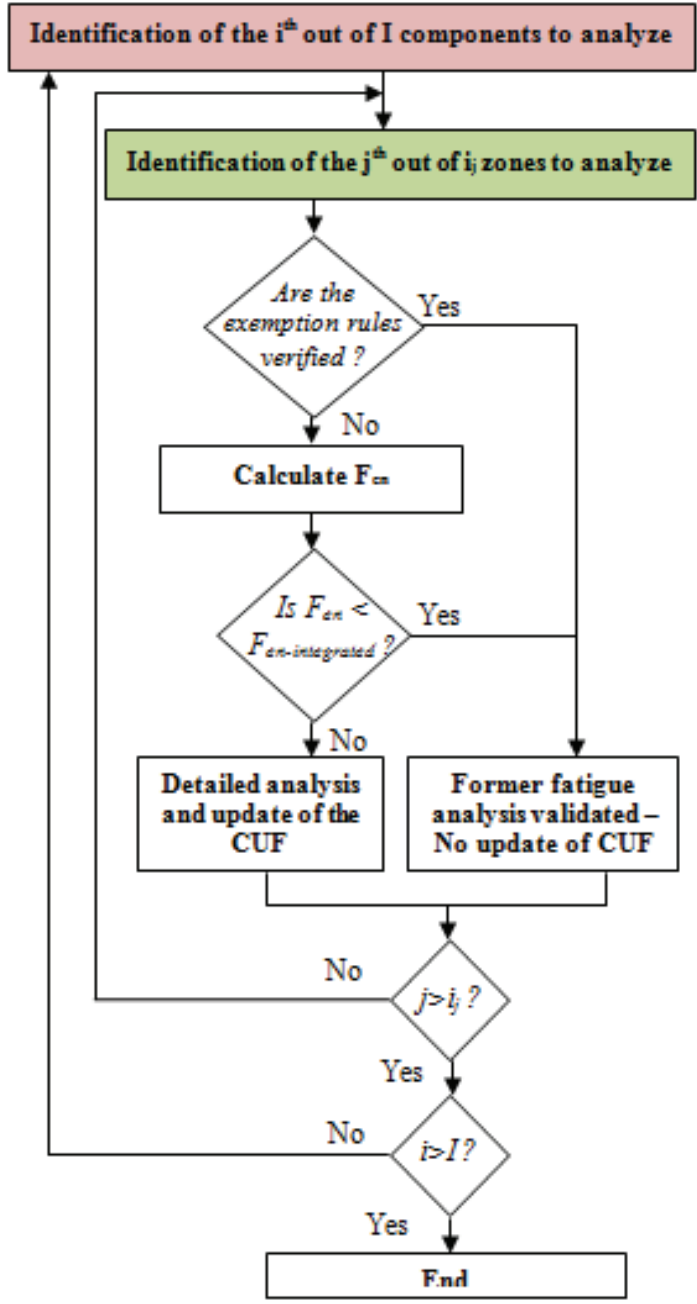

Figure 5 - Flowchart representing the overall methodology Annex A (advised to use maximum temperature for conservatism);

4) Sum the contributions of all these small increments and divide by the total strain amplitude according to the following formula: 


$$
\mathrm{F}_{\mathrm{en}}=\frac{\sum \mathrm{F}_{\mathrm{en}, \mathrm{j}} \Delta \varepsilon_{\mathrm{j}}}{\sum \Delta \varepsilon_{\mathrm{j}}}
$$

This enables to obtain the $\mathrm{F}_{\text {en }}$ factor for a transient combination and the same work has to be conducted for the various transient combinations. The RPP acknowledges the fact that, in some cases, it is not necessary to calculate the $\mathrm{F}_{\text {en }}$ factor for all transient combinations, but only for the combinations contributing significantly to the CUF.

In order to include the plastic correction factor $\mathrm{K}_{\mathrm{e}}$, as indicated in the second item above, two methods are given here for indication only. As a reminder, the RCC-M introduces two $\mathrm{K}_{\mathrm{e}}$ values, a $\mathrm{K}_{\mathrm{e} \text {-thermal }}$ calculated on the basis of the thermal contributions only and a $\mathrm{K}_{\mathrm{e} \text {-mechanical, calculated }}$ on the basis of the mechanical contributions (pressure, external loads).

The first method consists in correcting the strain as follows:

$\varepsilon_{\text {elpl }}(t)=\frac{1}{\varepsilon_{\max }-\varepsilon_{\min }}\left[\frac{K_{\mathrm{e}-\text { ther }} \mathrm{S}_{\mathrm{p}-\text { ther }}}{\mathrm{E}_{\text {ther }}}+\frac{\mathrm{K}_{\mathrm{e}-\text { mech }} \mathrm{S}_{\mathrm{p}-\mathrm{mech}}}{\mathrm{E}_{\text {mech }}}\right] \varepsilon_{\mathrm{el}}(\mathrm{t}) \quad$ or $\quad \varepsilon_{\mathrm{elpl}}(\mathrm{t})=\frac{1}{\varepsilon_{\max }-\varepsilon_{\min }}\left[\frac{2 \mathrm{~S}_{\text {alt }}{ }^{\prime}}{\mathrm{E}_{\mathrm{C}}}\right] \varepsilon_{\text {el }}(\mathrm{t})$

where $\varepsilon_{\mathrm{el}}$ is the elastic strain and $\varepsilon_{\text {elpl }}$ is the elasto-plastic strain, $\mathrm{S}_{\mathrm{p} \text {-ther }}$ and $\mathrm{S}_{\mathrm{p} \text {-mech }}$ are respectively the thermal and mechanical membrane plus bending stress ranges, $\mathrm{K}_{\mathrm{e} \text {-ther }}$ and $\mathrm{K}_{\mathrm{e} \text {-mech }}$ are respectively the thermal and mechanical plastic correction factors, $\mathrm{S}_{\mathrm{alt}}$ ' is the alternating stress amplitude and $\mathrm{E}_{\text {ther }}$ and $\mathrm{E}_{\text {mech }}$ are respectively the Young's modulus used for the thermal and the mechanical calculations This is equivalent to compressing or expanding the transient so that the maximum strain amplitude is reached.

The second method simply consists in multiplying the strain by a weighted $\mathrm{K}_{\mathrm{e}}$ value $\left(\mathrm{K}_{\mathrm{e}} \mathrm{avg}\right)$, defined as follows:

$$
\mathrm{K}_{\mathrm{e} \text { avg }}=\frac{\mathrm{K}_{\mathrm{e} \text { ther }} \mathrm{S}_{\mathrm{p} \text { ther }}+\mathrm{K}_{\mathrm{e} \text { mech }} \mathrm{S}_{\mathrm{p} \text { mech }}}{\mathrm{S}_{\mathrm{p} \text { ther }}+\mathrm{S}_{\mathrm{p} \text { mech }}}
$$

The analyst can choose either one of the methods or even use another methodology that ensures a conservative result.

\subsection{Comparison to the $F_{\text {en-integrated }}$}

Once the environmental factor is calculated for all transient pairs, an average environmental factor weighted by the partial usage factors can be calculated by using the following formula:

$$
\mathrm{F}_{\text {en }}=\frac{\sum_{1}^{\mathrm{n}} \mathrm{F}_{\text {en partial } j \mathrm{j}} \mathrm{FU}_{\text {partial } \mathrm{j}}}{\sum_{1}^{\mathrm{n}} \mathrm{FU}_{\text {partial } \mathrm{j}}}
$$

where $F U_{\text {partial }}$ and $F_{\text {en partial }}$ are respectively the partial usage factors and $F_{\text {en }}$ factors of the $n$ combinations

This factor represents the overall effect of the PWR water environment on a location that undergoes specific loads and transients. This quantity is then compared to the $\mathrm{F}_{\text {en-integrated. }}$

The $\mathrm{F}_{\text {en-integrated }}$ is a quantification of the amount of environmental effects that are already covered in the fatigue design curves. AREVA tests in PWR highlighted that when combining environmental effects with real transient profiles and/or representative surface finishes, the environmental effects were not as detrimental as expected. More information can be found in References [12][13][14][15]. 
The $\mathrm{F}_{\text {en-integrated }}$ can take two values: its minimum value is 3 and its maximum value is 5 . The value of 5 applies in cases where the location studied undergoes essentially thermal shocks such as the one shown on figure 6 .

These two values were derived using the AREVA test campaigns in conjunction with the new design curve proposed in this paper. For each data point, the amount of environmental effects included in the fatigue curve was calculated and the average of all the values found was taken. This enabled to obtain the values of 3 for tests with saw-tooth signals and of 5 for tests simulating cold and hot shocks.

In the case where the $\mathrm{F}_{\mathrm{en}}$ calculated above is smaller than the $\mathrm{F}_{\text {en-integrated, then the former }}$ CUF need not be updated. If the $\mathrm{F}_{\text {en }}$ calculated

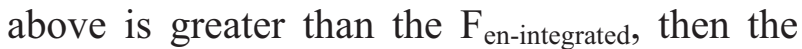
fatigue analysis should be updated and the partial usage factors should be multiplied by the ratio between the $F_{\text {en }}$ (either global or of the transient pair) and the $\mathrm{F}_{\text {en-integrated. The }} \mathrm{F}_{\text {en }}$ to take in this last calculation is left at the analysts' choice.

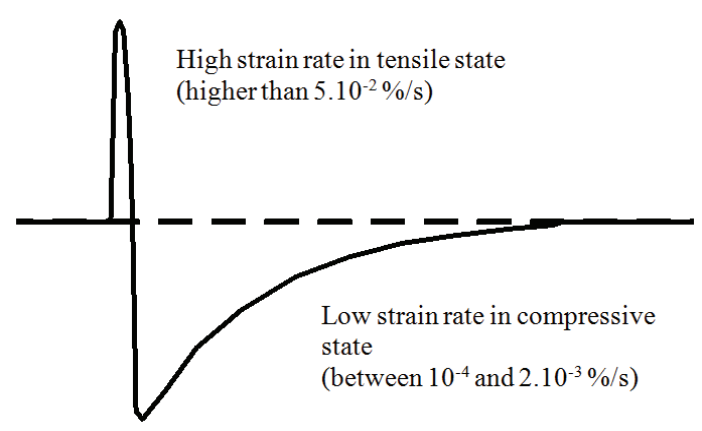

Figure 6 - Strain induced by a double cold and then hot thermal shock

\section{CONCLUSION}

In conclusion, this paper summarizes an approach that was submitted to the ASN/IRSN and AFCEN and is under review by these organizations (as of January 2015). This approach was submitted under two RCC-M RPP (Rules in Probatory Phase): the first rule presents a new fatigue curve for austenitic stainless steels while the second rule presents a method to include environmental effects into Stress Reports:

- The fatigue curve is built using the NUREG/CR-6909 as a starting point to which are applied factors of 10 on the number of cycles and of 1.4 on the strain amplitude;

- The environmental effects are included in the analysis by using a $F_{\text {en }}$ calculated using the formula for austenitic stainless steels from NUREG/CR-6909 [3] moderated by the $\mathrm{F}_{\text {en- }}$ integrated, which quantifies the amount of environmental effects already integrated in the fatigue curve.

This approach is less conservative than the NUREG/CR-6909 approach [1] but the preliminary sensitivity studies indicate an overall significant increase in the usage factors. Although the new and the former fatigue curves seem the same in a log-log plot, a factor of up to around 2 on life is reached. Moreover, the $F_{\text {en }}$ values obtained with NUREG/CR-6909 can go up to 14.06 , which still means that a maximum increase of 4.70 in the usage factors is possible with a $\mathrm{F}_{\text {en-integrated }}$ of a value of 3.00 .

Many countries are now working to extend the life of their existing power plants and it is necessary to perform an inventory of detrimental effects unaccounted for in the analyses and then include these effects in the Stress Report analyses. Their integration should altogether be reasonable so as not to push analysts towards using new and complex methodologies in Stress Reports, as these methods do not benefit from the experience feedback of conventional analysis methods. 


\section{ACKNOWLEDGMENTS}

The authors would like to thank L. Vincent for his ongoing testing on mean stress and mean strain as well as S. Bradaï for her work on the FABIME 2 test rig. The authors would additionally like to thank C. Amzallag, C. Faidy and J.A. Le Duff for all their work and contribution to the progress in the understanding and the assessment of the fatigue damage in general and environmental effects in particular. Finally, the authors address a thank you to C. Petesch, S. Chapuliot, S. Marie, J.P. Massoud and A. Fissolo for their participation in the fatigue technical work group on environmental effects.

\section{REFERENCES}

[1] NUREG/CR-6909, Rev. 0, "Effect of LWR Coolant Environments on the Fatigue Life of Reactor Materials," 2007, O.K. Chopra and W.J. Shack.

[2] Code Case ASME N-792-1, "Fatigue Evaluation Including Environmental Effects, Section III, Division 1," 2012.

[3] NUREG/CR-6909, Rev. 1, "Effect of LWR Coolant Environments on the Fatigue Life of Reactor Materials," O.K. Chopra and G.L. Stevens (Draft Report).

[4] RCC-M - Design and Construction Rules for mechanical components of nuclear PWR islands - 2007 edition with addenda in 2008, 2009 and 2010.

[5] PVP2013-97203, T. Métais \& al., "French Methodology Proposal for Environmentally Assisted Fatigue Assessment."

[6] PVP2014-28408, T. Métais \& al., "Status of French Methodology Proposal for Environmentally Assisted Fatigue Assessment."

[7] Codes for Nuclear Power Generation Facilities, "Environmental Fatigue Evaluation Method for Nuclear Power Plants," JSME S NF1-2006, Japan Society of Mechanical Engineers, Tokyo, Japan, 2006.

[8] Le Pécheur A., "Fatigue Thermique d'un acier inoxydable austénitique : influence de l'état de surface par une approche multi-échelles," PhD of Ecole Centrale Paris (ECP), 2008.

[9] Vincent L. et al., " On the high cycle fatigue behavior of a type 304L stainless steel at room temperature, » Int J Fatigue (2011), doi:10.1016/j.ijfatigue.2011.11.01.

[10] PVP2005-71064, Solomon H.D., Amzallag C., Vallee A.J. et De Lair R.E., "Influence of Mean Stress on the Fatigue Behavior of 304L SS in Air and PWR Water."

[11] Colin J., "Deformation History and Load Sequence Effects on Cumulative Fatigue Damage and Life Predictions," PhD of the University of Toledo (USA), 2009.

[12] PVP2014-28329, De Baglion L. et al., 2014, "Low Cycle Fatigue Behavior in Air and in PWR Water of a Type 304L Austenitic Stainless Steel Manufactured by Hot Isostatic Pressing Process".

[13] PVP 2008-61894, Le-Duff J.A. et al., "Effects of Surface Finish and Loading Conditions on the Low Cycle Fatigue Behavior of Austenitic Stainless Steel in PWR Environment. Comparison of LCF Test Results with NUREG/CR-6909 Life Estimations."

[14] PVP 2009-78129, Le-Duff J.A. et al., 2009, "Effects of Surface Finish and Loading Conditions on the Low Cycle Fatigue Behavior of Austenitic Stainless Steel in PWR Environment for Various Strain Amplitude Levels."

[15] PVP 2010-26027, Le-Duff J.A. et al., 2010, "Effect of Loading Signal and of Surface Finish on the Low Cycle Fatigue Behavior of 304L Stainless Steel in PWR Environment."

[16] PVP2009-77115, Namura Y. et al., "Optimization of environmental fatigue evaluation (Step 2)."

[17] PVP2009-77156, Fissolo A. and Stelmaszyk J.M., 2009, "A first investigation on cumulative fatigue life for a type 304-L stainless steel used for pressure water reactor."

[18] PVP2005-71594, Curtit F. and Stephan J.M., 2005, "INTHERPOL Thermal Fatigue Test."

[19] Ancelet O., 2006, "Etude de l'amorçage et de la propagation des fissures sous chargement multiaxial," Thèse de l'Université de Poitiers (in French).

[20] PVP2013-97200, Bradai S. et al., 2013, "Crack Initiation under Equibiaxial Fatigue, Development of a particular Equibiaxial Fatigue Device." 
[21] PVP2014-28421, Bradaï S. et al., 2014, "Equi-Biaxial Loading Effect on Austenitic Stainless Steel Fatigue Life."

[22] Rupil J. et al., 2011, "Essais de fatigue équibiaxiaux à grand nombre de cycles sur un acier inoxydable austénitique AISI 304L: Utilisation de la corrélation d'images pour mesurer les amplitudes de déformation et détecter les réseaux de fissures," 20ème congrès Français de Mécanique, 29th August-2nd September (in French).

[23] Barbier G., 2009, "Fatigue biaxiale à grand nombre de cycles : étude expérimentale et modèle d'endommagement à deux échelles probabiliste," $\mathrm{PhD}$ from ENS Cachan (in French).

[24] Haddar N., 2003, "Fatigue thermique d'un acier austénitique 304L: simulation de l'amorçage et de la croissance des fissures courtes en fatigue isotherme et anisotherme," $\mathrm{PhD}$ from Ecole Nationale Supérieure des Mines de Paris (in French).

[25] PVP2014-28409, Blatman G. et al., 2014, "Statistical Analyses of High Cycle Fatigue French Data for Austenitic SS."

[26] ISO 16269-6, "Statistical interpretation of data - Part 6: Determination of statistical tolerance intervals", 2014, ISO 16269-6:2014(F)

[27] Millar, R., 2011, "Maximum Likelihood Estimation and Inference: With Examples in R," SAS and ADMB, John Wiley \& Sons.

[28] Koenker, R. and G. Bassett, 1978, "Regression quantiles," Econometrica 46, 33-50.

[29] EPRI Report 1024995, "Environmentally Assisted Fatigue Screening - Process and Technical Basis for Identifying EAF Limiting Locations," EPRI, 2012.

[30] Courtin S., Lefrançois A., Le Duff J. A. And Le Pécheur A., 2012, "Environmentally Assisted Fatigue Assessment Considering an Alternative Method to the ASME Code Case N-792," ASME PVP2012-78088, ASME 2012 Pressure Vessels and Piping Conference, ASME, Toronto, Canada.

Table 4 - Summary of the data used for the RPP

\begin{tabular}{|c|c|c|c|c|c|c|}
\hline Lab & Sponsor & Steel & Material (RCC-M) & Air data & $\begin{array}{l}\text { PWR } \\
\text { data }\end{array}$ & $\begin{array}{l}\text { Reference } \\
\text { (when } \\
\text { publicly } \\
\text { available) }\end{array}$ \\
\hline Les Renardières & EDF & $\begin{array}{l}\text { 304L / 316L / } \\
\text { Duplex moulé }\end{array}$ & $\begin{array}{c}\text { Z3 CN 20-09M, Z2 CN } \\
18-10, \text { Z2 CND 17-12, Z2 } \\
\text { CND 17-13 }\end{array}$ & 173 & 0 & [8] \\
\hline $\begin{array}{l}\text { Creusot Loire } \\
\text { Unieux }\end{array}$ & CL Unieux & $316 \mathrm{~L}$ & $\begin{array}{c}\text { Z2 CND 17-12, Z2 CND } \\
17-13\end{array}$ & 81 & 0 & \\
\hline SRMA - CEA & $\mathrm{CEA} / \mathrm{EDF}$ & 304L / 316L & $\begin{array}{c}\text { Z2 CND 17-13, Z2 CND } \\
18-10, \text { Z2 CN 18-10 }\end{array}$ & 98 & 0 & [9] \\
\hline CEAT & EDF & 304L / 316L & $\begin{array}{c}\text { Z2 CN 18-10, Z2 CND } \\
17-12\end{array}$ & 42 & 0 & \\
\hline $\begin{array}{c}\text { General Electric } \\
\text { (USA) }\end{array}$ & EDF & $304 \mathrm{~L}$ & $\mathrm{Z} 2 \mathrm{CN} 18-10$ & 22 & 32 & {$[10]$} \\
\hline CETIM & EDF & Duplex moulé & Z3 CN 20-09M & 10 & 0 & \\
\hline INSA Rouen & EDF & $304 \mathrm{~L}$ & Z2 CN 18-10 & 17 & 0 & \\
\hline UT Compiègne & $\begin{array}{c}\text { UT } \\
\text { Compiègne }\end{array}$ & $304 \mathrm{~L}$ & $\mathrm{Z} 2 \mathrm{CN} 18-10$ & 5 & 0 & \\
\hline $\begin{array}{l}\text { Toledo University } \\
\text { (USA) }\end{array}$ & $\mathrm{EDF}$ & $304 \mathrm{~L}$ & $\mathrm{Z} 2 \mathrm{CN} 18-10$ & 52 & 0 & [11] \\
\hline LMT Cachan & $\begin{array}{c}\text { EDF / CEA / } \\
\text { AREVA }\end{array}$ & $304 \mathrm{~L}$ & Z2 CN 18-10 & 14 & 0 & \\
\hline MHI & EDF & $304 \mathrm{~L}$ & $\mathrm{Z2} \mathrm{CN} 18-10$ & 0 & 13 & \\
\hline ENSMA & AREVA & $304 \mathrm{~L}$ & Z2 CN 18-10 & 22 & 7 & {$[12]$} \\
\hline CT Le Creusot & AREVA & $304 \mathrm{~L}$ & $\mathrm{Z} 2 \mathrm{CN} 18-10$ & 24 & 31 & $\begin{array}{c}{[13][14][1} \\
5]\end{array}$ \\
\hline & & & TOTAL & 560 & 83 & \\
\hline
\end{tabular}




\section{Material variability and data scatter}

1-Evaluation of $A_{i, m}, A_{i, 5}$ and $A_{i, 95}$ for each data sub-group

\section{2-Evaluation of $\mathbf{A}_{\mathbf{m}}$ and sd for all the} data set

3- Calculation of the $10^{ \pm 2 s d}[16]$

\section{Component effect}

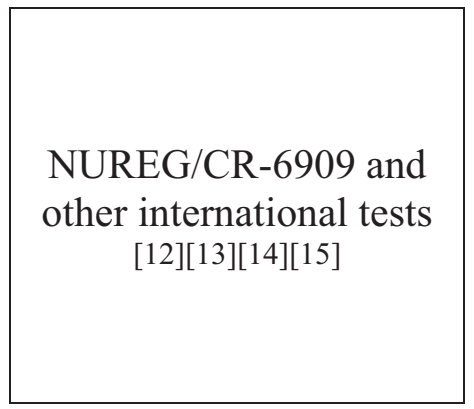

\section{$2.0-3.0$ (Air) 1.5 - 2.5 (PWR)}

\section{Loading effect}

NUREG/CR-6909 and other international tests [17][18][19][20][21][22][23][24]

\section{$2.1-2.8$}

Analytical evaluation of the global coefficient using $\mathrm{A}_{\mathrm{m}}$ and $\mathrm{sd}$ for the Material variability and assuming a lognormal distribution for the two other effects

\section{Global coefficient : 7.0 (air) - 6.0 (PWR)}

Figure 7 - Summary of the RPP contents for the fatigue curve

\section{ANNEX A - $F_{E N}$ FORMULAS$$
\mathrm{F}_{\mathrm{en}}=\mathrm{e}^{-\mathrm{T}^{\prime} \mathbf{O}^{\prime} \dot{\dot{\varepsilon}},}
$$

where

$T^{\prime}=0 \quad$ for $T<100^{\circ} \mathrm{C}$

$T^{\prime}=(T-100) / 250 \quad$ for $100^{\circ} \mathrm{C} \leq T \leq 325^{\circ} \mathrm{C}$

$\dot{\varepsilon}^{\prime}=0 \quad$ for $\dot{\varepsilon}>10 \% / \mathrm{s}$

$\dot{\varepsilon}{ }^{\prime}=\ln (\dot{\varepsilon} / 10) \quad$ for $0.0004 \% / s \leq \dot{\varepsilon} \leq 10 \% / s$

$\dot{\varepsilon} \dot{\varepsilon}^{\prime}=\ln (0.0004 / 10) \quad$ for $\dot{\varepsilon}<0.0004 \% / s$

$O^{\prime}=0.29 \quad$ for DO less than 0.1 ppm (i.e. PWR or BWR HWC water - all wrought and cast SSs and heat treatments and SS weld metals)

$O^{\prime}=0.29 \quad$ for DO greater or equal to $0.1 \mathrm{ppm}$ (i.e. BWR NWC water - sensitized high-carbon wrought and cast SSs)

$O^{`}=0.14 \quad$ for DO greater or equal to $0.1 \mathrm{ppm}$ (i.e. BWR NWC water - all wrought SSs except sensitized high-carbon SSs) 